Proceedings of the 31st Annual Meeting of the Brazilian Embryo Technology Society (SBTE); Cabo de Santo Agostinho, PE, Brazil, August 17th to 19th, 2017.

\title{
Postnatal consequences of assisted reproductive technologies in cattle
}

\author{
Peter J. Hansen ${ }^{1,3}$, Luiz Gustavo B. Siqueira ${ }^{2}$ \\ ${ }^{1}$ Department of Animal Sciences, D.H. Barron Reproductive and Perinatal Biology Research Program, and Genetics Institute, \\ University of Florida, Gainesville, FL, USA. \\ ${ }^{2}$ Embrapa Gado de Leite, Juiz de Fora, MG, Brazil.
}

\begin{abstract}
Experiments in mice and clinical observations in humans are indicative that adult phenotype can be altered in offspring derived from embryos that were subjected to culture or that were produced by the combination of in vitro oocyte maturation, fertilization and embryonic development (in vitro production; IVP). The most commonly observed changes are in body and organ size, growth rate, cardiovascular function and regulation of glucose homeostasis. In cattle, IVP is associated with increased birth weight and neonatal death loss but little is known about the long-term consequences of embryo technologies. Recently, postnatal characteristics were compared between females born as a result of artificial insemination, IVP using conventional semen, IVP using reverse X-sorted semen, and multiple ovulation - embryo transfer. Females born following IVP using reverse $\mathrm{X}$-sorted semen produced less milk, milk fat, and milk protein than females in the other three groups, which were similar to each other. These results point out the importance of 1) examining other data sets to examine long-term impact of assisted reproductive technologies on adult physiology and performance and 2) evaluating whether use of sexed semen alters the adult phenotype when used for artificial insemination.
\end{abstract}

Keywords: dairy cattle, in vitro fertilization, milk yield, sexed semen.

\section{Introduction: The promise and perils of assisted reproductive technologies}

Embryo technologies, whether involving superovulation (multiple ovulation - embryo transfer; MOET) or in vitro production (IVP), create multiple opportunities for those involved in production of dairy and beef cattle. Both MOET and IVP were developed primarily as a method for increasing the number of offspring from genetically-valuable females. Rates of genetic gain can be increased by combining genomic testing and embryo transfer (Pryce et al., 2010; Thomasen et al., 2016; Kaniyattam et al., 2017). Use of embryo transfer in a commercial dairy can be profitable when costs of embryo production are low and the excess heifers sold from the herd are valuable (Kaniyattam et al., 2017). Embryo transfer can also improve fertility as compared to artificial insemination (AI) for subpopulations of cows with low fertility - those exposed to heat stress and designated as repeat breeding females (Fig. 1). In addition, embryo transfer allows rapid change in the breed composition of a herd (Wheeler et al., 2006) and can allow production of crossbred animals without the need to maintain large numbers of purebred females. Moreover, IVP is an efficient method for using sexed semen (Wheeler et al., 2006; Pontes et al., 2010; Rasmussen et al., 2013; Pellegrino et al., 2016) and multiple embryos can be produced using a single straw of semen.

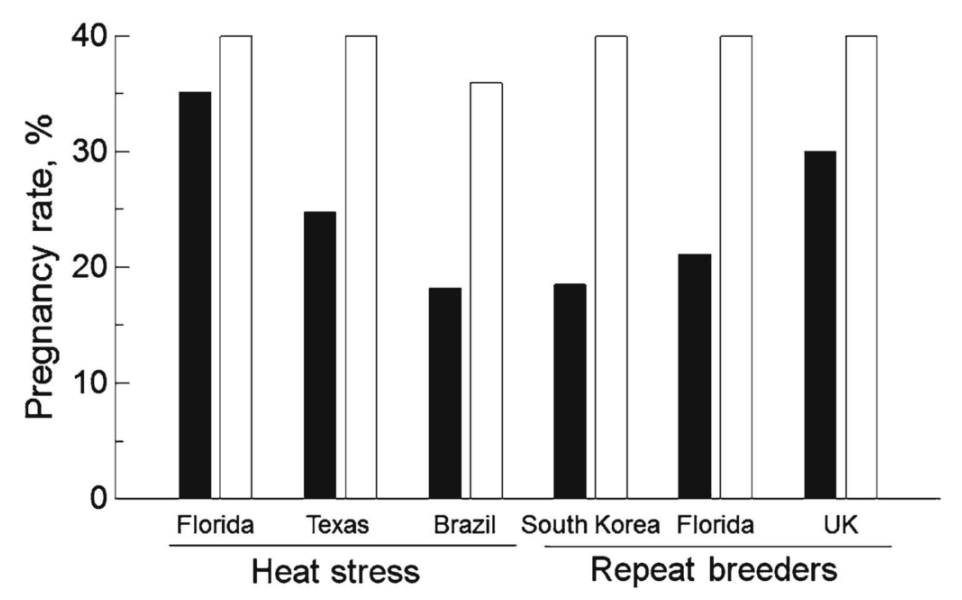

Figure 1. One of the promises of embryo transfer - improved pregnancy rates for cows that are heat-stressed or classified as repeat-breeders (third or more consecutive attempt to establish pregnancy). The figure is reproduced from Hansen (2014) with permission of Springer. Shown are examples of studies in lactating dairy cows in which pregnancy rates were improved by embryo transfer (open bar) as compared to artificial insemination (filled bar). Data from heat stress experiments are from Block et al. (2010; Florida), Stewart et al. (2011; Texas) and Vasconcelos et al. (2011; Brazil). Data from repeat breeder studies are from Son et al. (2007; South Korea), Block et al. (2010; Florida) and Canu et al. (2010; UK). 
Despite the benefits that accrue from embryo technologies, some of the promise is not always realized because of aberrant embryonic development. It is well known that the IVP embryo can differ from the embryo produced in vivo in terms of morphology, gene expression and freezability (Hansen, 2006, 2014). Even superovulation can cause changes in embryonic developmental competence, gene expression and DNA methylation (Markert-Velker et al., 2010; Gad et al., 2011). One consequence of embryo production in vitro is that pregnancy rates are often lower than for MOET (Pontes et al., 2009; Siqueira et al., 2009). Moreover, pregnancy failure for pregnancies established following transfer of an IVP embryo can be elevated (Stewart et al., 2011) although this is not always seen (Pereira et al., 2016). Calves derived from IVP embryos have also been reported to experience increased neonatal mortality (van Wagtendonk-de Leeuw et al., 1998; Bonilla et al., 2014). Increased perinatal deaths can be ascribed in large part to abnormal offspring syndrome (Farin et al., 2010) which is often manifested as calves born with abnormally large body size. An example of a fetus derived from an IVP embryo that experienced excessive somatic growth is shown in Fig. 2.

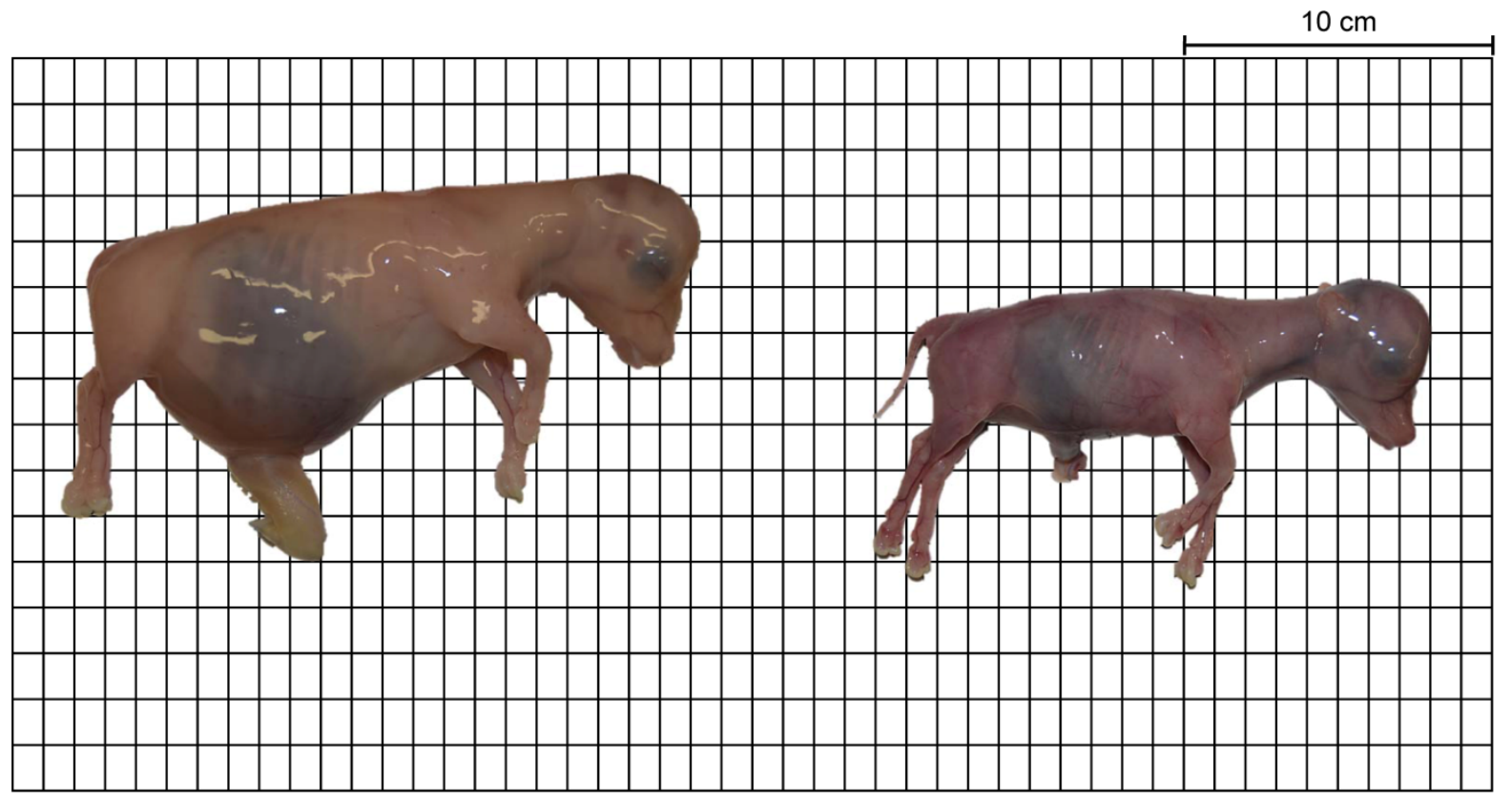

Figure 2. Excessive fetal growth at day 86 of gestation associated with in vitro embryo production. The fetus on the left was produced in vitro and the embryo on the right was produced by AI. The image is reproduced from Siqueira et al. (2017b) with permission of Oxford University Press.

\section{Evidence from other species that culture of embryos can affect postnatal phenotype}

Alterations in the function of the IVP embryo mean that one or more of the processes of oocyte maturation, sperm capacitation, fertilization, or embryonic development are not optimal. To be sure, the environment in which these events occur in vitro does not reproduce in all respects the environment in which these events occur in vivo. It is known from studies in various mammalian species that alterations in maternal environment during periods of oocyte maturation (Watkins et al., 2008; Turner and Robker, 2015) and preimplantation embryonic development (Fleming et al., 2015; Hansen, 2015; Hansen et al., 2016) can cause a change in developmental processes that have consequences for the resulting offspring in the postnatal period. This phenomenon, referred to as developmental programming, is likely to result either from epigenetic changes in the embryo that persist into later life or to a change in specific developmental processes that affect derived tissues or organs. In many cases, the change in phenotype caused by environmental cues is different for male offspring than for female offspring (Hansen et al., 2016). Effects of environment on the sire can also have impacts on his offspring after birth (Rando and Simmons, 2015; Schagdarsurengin and Steger, 2016).

Given the importance of parental environment for shaping postnatal phenotype, it is reasonable to question whether either IVP, which causes large perturbations in the environment of the gametes and embryo, or MOET, which is associated with ovulation of follicles not normally destined to ovulate and an abnormal endocrine environment, can change the phenotype of the animals produced using such technologies. This question has been addressed in the human, for embryos produced in vitro, and in the mouse, for embryos either produced and cultured in vitro or produced in vivo and cultured in vitro.

Studies in the human are difficult to interpret because of possible biases associated with the choice by a patient to seek IVP treatment. However, epidemiological studies have been conducted in which inclusion criteria were developed to minimize bias between children born from IVP vs control children. Increased frequency of hypertension in pre-adolescent and adolescent children born using IVP has been frequently observed (Scherrer $e t$ $a l ., 2015)$. There are also data from the Netherlands that children and adolescents born as a result of IVP tend to be fatter than controls (Ceelen et al., 2007). In contrast, 
educational performance was not associated with IVP (Wagenaar et al., 2008).

Controlled experiments in the mouse also show that production of embryos in vitro can cause alterations in postnatal phenotype and that some perturbations occur in a sex-specific context. For example, mice derived from embryos that developed in vitro from the two-cell stage exhibited altered behavior in the Morris water maze task, with male offspring being more affected than females (Ecker et al., 2004). In another study, Watkins et al. (2007) compared offspring derived from three procedures: transfer of embryos cultured from the two-cell to blastocyst stages of development, transfer of embryos flushed from the reproductive tract at the blastocyst stage, and natural mating. Among other endpoints studied, postnatal growth was generally similar between groups but mice derived from cultured embryos had higher systolic blood pressure than other groups at 21 weeks of age. Subsequently, Calle et al. (2012) examined male offspring derived from embryos cultured from the one-cell to blastocyst stages of development. Males derived from cultured embryos were less fertile than males derived from embryos produced in vivo as reflected by epididymal sperm count, sperm motility and the percent of females pregnant after breeding. In addition, male offspring, but not female offspring, experienced reduced clearance of an administered dose of glucose.

Specific components of culture medium used to produce mouse embryos in vitro have also been examined for their programming effects. In one experiment, addition of serum to the medium of embryos cultured from the one-cell to blastocyst stages resulted in offspring with altered behavioral responses in males and females, increased adult weight in females at 31 weeks of age and later and increased liver and heart size in both sexes at 20 month of age (FernándezGonzalez et al., 2004). Using in vitro fertilization and embryo culture, Donjacour et al. (2014) evaluated effect of embryo culture medium on properties of the resultant offspring. Culture media evaluated were KSOM and Whitten medium. Offspring derived from embryos cultured in KSOM were similar to offspring derived from controls (either from transfer of flushed blastocysts or produced from natural mating). In contrast, male offspring from embryos cultured in Whitten medium experienced increased body weight during the first 19 weeks of life, enlarged left heart and reduced response to a glucose tolerance test compared to male offspring from other treatments. There were no differences between groups for female offspring.

Finally, Rexhaj et al. (2015) evaluated whether addition of melatonin to embryo culture medium would reduce developmental abnormalities associated with in vitro fertilization and embryo culture. Results indicated that in vitro fertilization and embryo culture caused various vascular abnormalities in offspring and associated changes in DNA methylation and that addition of melatonin to the culture medium prevented these changes.

The phenotype expressed by mice derived by IVP may depend upon the pre- and postnatal environment. Thus, for example, Strata et al. (2015) observed no difference in behavior between offspring derived from in vitro fertilization and embryo culture vs those produced by natural mating when the prenatal diet was a typical rodent diet and the postnatal diet was designed to mimic a moderately high-fat diet. In contrast, feeding a low-protein diet prenatally and a high far diet postnatally was associated with differences in behavior between the mice derived from IVP $v s$. natural mating. Similarly, Cerny et al. (2017) observed no differences in glucose tolerance, insulin sensitivity, or insulin stimulation of muscle blood flow in vivo between male mice derived by IVP $v s$. those derived in vivo (females were not observed). However, when offspring were fed a high fat diet, those produced in vitro were fatter, experienced fasting hyperinsulinemia and hyperglycemia, and had reduced utilization of glucose in response to insulin treatment.

Transgenerational effects of embryo culture have also been reported. Mahsoudi et al. (2007) examined properties of mice derived from cultured embryos as compared to those derived from embryos that developed in vivo (F0). In addition, mice of the next two generations (F1 and F2) were also evaluated. There were few differences between mice in the F0 generation. However, mice derived from cultured embryos had lower weight at weaning and higher thyroid weight and epididymis weight at maturity. Differences in weaning weight persisted in the F1 generation and, additionally, F1 mice descended from cultured embryos had higher brain, pituitary and kidney weights and lower prostate weights. There were no differences between groups in body weight in the F2 generation and other measurements were not taken. Calle et al. (2012) also examined the F1 and F2 descendants of males offspring derived from cultured embryos. The F1 and F2 male offspring of males derived by embryo culture had reduced clearance of glucose in the glucose tolerance test and increased liver size but there was no effect on female descendants.

\section{First evidence that an assisted reproductive technology can affect adult phenotype in cattle}

Studies in mice and humans are indicative that the entire process of IVP or, for mice, embryo culture, can change the adult phenotype of the offspring. However, results also indicate the degree to which phenotype is modified can depend on characteristics of the culture conditions, the sex of the offspring, and the environmental conditions offspring experience in postnatal life.

We recently analyzed a dataset from a registered Holstein dairy in north Florida that makes extensive use of embryo transfer using both IVP and MOET (Siqueira et al., 2017a). Included in the study were females born from June, 2012 to April, 2014. This resulted in records for 3,465 AI females born alive (2,037 with production records for first lactation), 249 heifer calves born alive following MOET (183 with lactation records), 345 heifer calves born alive following IVP with fertilization using conventional 
semen (IVP-conv; 218 with lactation records) and 685 heifers born alive from IVP with fertilization using reverse X-sorted semen (IVP-sexed; 430 with lactation records)

As is true for studies on the consequences of human IVP, animals were not randomly assigned to reproductive technique. Rather, the managers of the farm assigned animals to the appropriate reproductive technique based on the breeding and management objectives of the farm. One difference between groups was for genomic estimates of predicted transmitting abilities (PTA) for economically important traits. For example, the genomic PTA for milk averaged $203 \mathrm{~kg}$ for AI, $290 \mathrm{~kg}$ for IVP-conv calves, 284 for IVP-sexed calves and 235 for MOET calves. Accordingly, lactational performance of the offspring was adjusted by using genomic PTA for milk, fat or protein as a covariate.

Heifer birth weight was significantly affected by reproductive technique but differences between groups were numerically small. In particular, calves born by IVP-conv $(39.4 \pm 0.3 \mathrm{~kg})$ and IVP-sexed $(39.0$ $\pm 0.2)$ were larger than AI calves $(38.5 \pm 0.1 \mathrm{~kg})$; values for MOET were intermediate and not different from any group $(38.7 \pm 0.4 \mathrm{~kg})$. Weaning weight and average daily gain from birth to weaning did not differ between groups. However, weight at first breeding was highest for IVP-sexed $(355 \pm 2 \mathrm{~kg})$, intermediate for IVP-conv $(351 \pm 3 \mathrm{~kg})$ and MOET $(346 \pm 3 \mathrm{~kg})$ and lowest for AI $(344 \pm 0.8 \mathrm{~kg})$. Effects of treatment on average daily gain from weaning to breeding paralleled results for weight at breeding.

There was no significant difference between groups for age at first calving or interval from calving to conception in the first lactation. There were, however, significant effects of reproductive technique on lactational performance during first lactation (Table 1). In particular, IVF-sexed females produced less milk, fat and protein than cows of other groups. The difference in average projected actual milk yield between cows produced using IVF-sexed and cows produced by AI was $321 \mathrm{~kg}$.

Table 1. Effects of technique used to produce a pregnancy on first-lactation milk yield of the resultant offspring after adjusting for genomic predicted transmitting ability for yield ${ }^{1,2,3}$.

\begin{tabular}{lccccc}
\hline & AI & IVP-conv & IVP-sexed & MOET & P-value \\
\hline Projected actual milk yield, 305 days (kg) & $11038 \pm 31^{\mathrm{a}}$ & $10946 \pm 100^{\mathrm{ab}}$ & $10717 \pm 76^{\mathrm{b}}$ & $10891 \pm 149^{\mathrm{ab}}$ & 0.0014 \\
Projected actual fat yield, 305 days (kg) & $388.3 \pm 1.2^{\mathrm{a}}$ & $385.6 \pm 3.9^{\mathrm{ab}}$ & $377.1 \pm 3.0^{\mathrm{b}}$ & $384.7 \pm 5.8^{\mathrm{ab}}$ & 0.0072 \\
Projected actual protein yield, 305 days (kg) & $334.6 \pm 1.0^{\mathrm{a}}$ & $336.5 \pm 3.3^{\mathrm{a}}$ & $327.1 \pm 2.5^{\mathrm{b}}$ & $331.2 \pm 4.8^{\mathrm{ab}}$ & 0.0318
\end{tabular}

${ }^{1}$ Abbreviations used are as follows: AI: artificial insemination; IVP-conv: in vitro embryo production with conventional semen; IVP-sexed: in vitro embryo production with reverse X-sorted semen; MOET: multiple ovulation and embryo transfer; PTA: predicted transmitting ability; DPR: daughter pregnancy rate. ${ }^{2}$ The P-values are for the main effect of reproductive technique. Within a row, means without a common superscript differ at $\mathrm{P}<0.05 .{ }^{3}$ Data are from Siqueira et al. $(2017 \mathrm{a})$.

\section{Implications of bovine data}

Caution must be taken when interpreting these data. Most importantly, neither dams nor sires of the animals studied were assigned randomly to treatment. Differences in genomic estimates of lactational performance were corrected for but other differences could have existed. Also, while to the best of our knowledge, calves were managed similarly after birth regardless of reproductive technique, one cannot discount some unknown difference in management. For example, fetal sex can affect milk yield in the existing lactation (Hinde et al., 2014) and it is conceivable that sex ratio of pregnancies in first lactation varied between groups. Given that culture system affected the nature of developmental programming in mice (FernándezGonzalez et al., 2004; Donjacour et al., 2014; Rexhaj et al., 2015), the effect of being born using a specific reproductive technology might depend on the particular details of the techniques employed. Accordingly, general conclusions should not be derived until the performance of animals derived from IVP or MOET is examined in a wide range of settings.

With these caveats in mind, the results of Siqueira et al. (2017a) indicate that IVP was only associated with adverse lactational outcomes when sexed semen produced using reverse sorting was used for fertilization. The fact that milk yield of IVP-conv and MOET cows was not different from that of AI cows may mean that the physiological processes controlling milk synthesis and secretion are less amenable to programming errors than for traits measured in mice and humans, i.e., cardiovascular function, growth rate, and regulation of glucose metabolism.

An important question to address is the mechanism by which use of reverse-sorted semen caused altered postnatal phenotype. The sorting process damages spermatozoa so that fertilization rate in vitro is compromised (Wheeler et al., 2006; Rasmussen et al., 2013). Perhaps, reverse sorting reduces non-nuclear components of sperm that are delivered to the oocyte at fertilization, for example sperm-borne miRNA (Liu et al., 2012). Also, a possible delay in fertilization due to damaged sperm could conceivably result in oocyte aging, which has negative consequences for the oocyte and subsequent embryo (Agung et al., 2006; Koyama et al., 2014). A compelling question is whether use of sexed semen can alter adult phenotype only when included as part of IVP with reverse-sorting or whether similar effects would be manifest using IVP with semen sorted before cryopreservation. Indeed, it is possible that alterations in adult capacity for milk yield could be caused by use of sex-sorted semen for AI. There is one report that incidence of stillbirths is increased among 
bull calves born to females inseminated with X-sorted sperm (DeJarnette et al., 2009). There is also a report from a smaller study that incidence of stillbirth is higher among females born following AI with X-sorted sperm (Healy et al., 2013). The adult performance of calves born using AI with sexed semen remains to be determined and should be assessed.

\section{Future directions}

Observations that assisted reproductive technologies can result in alterations in the resultant offspring are part of a larger and still-emerging story that postnatal phenotype of mammalsis can be modified by the microenvironment of the embryo during the preimplantation period (Fleming et al., 2015; Hansen, 2015; Hansen et al., 2016) and of the gametes from which it was derived (Watkins et al., 2008; Turner and Robker, 2015; Rando and Simmons, 2015; Schagdarsurengin and Steger, 2016). Thus, production efficiency of an animal may depend not only on its genotype and the environment in which it is raised but also on changes to its developmental program early in gestation. Understanding the nature of developmental programming may lead to novel interventions to improve efficiency of livestock production.

\section{References}

Agung B, Otoi T, Wongsrikeao $\mathbf{P}$, Taniguchi $\mathbf{M}$, Shimizu R, Watari H, Nagai T. 2006. Effect of maturation culture period of oocytes on the sex ratio of in vitro fertilized bovine embryos. $J$ Reprod Dev, 52:123-127.

Block J, Bonilla L, Hansen PJ. 2010. Efficacy of in vitro embryo transfer in lactating dairy cows using fresh or vitrified embryos produced in a novel embryo culture medium. J Dairy Sci, 93:5234-2542.

Bonilla L, Block J, Denicol AC, Hansen PJ. 2014 Consequences of transfer of an in vitro-produced embryo for the dam and resultant calf. $J$ Dairy Sci,97:229-239.

Calle A, Miranda A, Fernandez-Gonzalez $R$, Pericuesta E, Laguna R, Gutierrez-Adan A. 2012 Male mice produced by in vitro culture have reduced fertility and transmit organomegaly and glucose intolerance to their male offspring. Biol Reprod, 87:34. doi: 10.1095/biolreprod.112.100743.

Canu S, Boland M, Lloyd GM, Newman M, Christie MF, May PJ, Christley RM, Smith RF, Dobson H. 2010. Predisposition to repeat breeding in UK cattle and success of artificial insemination alone or in combination with embryo transfer. Vet Rec, 167:44-51.

Ceelen M, van Weissenbruch MM, Roos JC, Vermeiden JP, van Leeuwen FE, Delemarre-van de Waal HA. 2007. Body composition in children and adolescents born after in vitro fertilization or spontaneous conception. J Clin Endocrinol Metab, 92:3417-3423.

Cerny D, Sartori C, Rimoldi SF, Meister T, Soria R, Bouillet E, Scherrer U, Rexhaj E. 2017. Assisted reproductive technologies predispose to insulin resistance and obesity in male mice challenged with a high fat diet. Endocrinology, 158:1152-1159.

DeJarnette JM, Nebel RL, Marshall CE. 2009. Evaluating the success of sex-sorted semen in US dairy herds from on farm records. Theriogenology, 71:49-58.

Donjacour A, Liu X, Lin W, Simbulan R, Rinaudo PF. 2014. In vitro fertilization affects growth and glucose metabolism in a sex-specific manner in an outbred mouse model. Biol Reprod, 90:80. doi: 10.1095/biolreprod.113.113134.

Ecker DJ, Stein P, Xu Z, Williams CJ, Kopf GS, Bilker WB, Abel T, Schultz RM. 2004. Long-term effects of culture of preimplantation mouse embryos on behavior. Proc Natl Acad Sci USA, 101:1595-600.

Farin CE, Farmer WT, Farin PW. 2010. Pregnancy recognition and abnormal offspring syndrome in cattle. Reprod Fertil Dev, 22:75-87.

Fernández-Gonzalez $\mathbf{R}$, Moreira $\mathbf{P}$, Bilbao $\mathbf{A}$, Jiménez A, Pérez-Crespo M, Ramírez MA, Rodríguez De Fonseca F, Pintado B, Gutiérrez-Adán A. 2004. Long-term effect of in vitro culture of mouse embryos with serum on mRNA expression of imprinting genes, development, and behavior. Proc Natl Acad Sci USA, 101:5880-5885.

Fleming TP, Watkins AJ, Sun C, Velazquez MA, Smyth NR, Eckert JJ. 2015. Do little embryos make big decisions? How maternal dietary protein restriction can permanently change an embryo's potential, affecting adult health. Reprod Fertil Dev, 27:684-692.

Gad A, Besenfelder U, Rings F, Ghanem N, SalilewWondim D, Hossain MM, Tesfaye D, Lonergan P, Becker A, Cinar U, Schellander K, Havlicek V, Hölker M. 2011. Effect of reproductive tract environment following controlled ovarian hyperstimulation treatment on embryo development and global transcriptome profile of blastocysts: implications for animal breeding and human assisted reproduction. Hum Reprod, 26:1693-707.

Hansen PJ. 2006. Realizing the promise of IVF in cattle--an overview. Theriogenology, 65:119-125.

Hansen PJ. 2014. Current and future assisted reproductive technologies for mammalian farm animals. Adv Exp Med Biol, 752:1-22.

Hansen, PJ. 2015. Developmental programming in the preimplantation period: can it be exploited to enhance postnatal function in cattle? Anim Reprod, 12:428-436.

Hansen PJ, Dobbs KB, Denicol AC, Siqueira LG. 2016. Sex and the preimplantation embryo: implications of sexual dimorphism in the preimplantation period for maternal programming of embryonic development. Cell Tissue Res, 363:237-247.

Healy AA, House JK, Thomson PC. 2013. Artificial insemination field data on the use of sexed and conventional semen in nulliparous Holstein heifers. $J$ Dairy Sci, 96:1905-1914.

Hinde K, Carpenter AJ, Clay JS, Bradford BJ. 2014. Holsteins favor heifers, not bulls: biased milk production programmed during pregnancy as a function of fetal sex. PLoS One, 9:e86169.

Kaniyamattam K, Block J, Hansen PJ, De Vries A. 2017. Comparison between an exclusive in vitroproduced embryo transfer system and artificial 
insemination for genetic, technical, and financial herd performance. J Dairy Sci, 100: 5729-5745.

Koyama K, Kang SS, Huang W, Yanagawa Y, Takahashi Y, Nagano M. 2014. Aging-related changes in in vitro-matured bovine oocytes: oxidative stress, mitochondrial activity and ATP content after nuclear maturation. J Reprod Dev, 60:136-142.

Liu W-M, Pang RTK, Chiu PCN, Wong BPC, Lao K, Lao, KF, Yeung WSB. 2012. Sperm-borne microRNA-34c is required for the first cleavage division in mouse. Proc Natl Acad Sci USA, 109:490494.

Mahsoudi B, Li A, O'Neill C. 2007. Assessment of the long-term and transgenerational consequences of perturbing preimplantation embryo development in mice. Biol Reprod, 77:889-896.

Market-Velker BA, Zhang L, Magri LS, Bonvissuto AC, Mann MRW. 2010. Dual effects of superovulation: loss of maternal and paternal imprinted methylation in a dose-dependent manner. Hum Mol Genet, 19:36-51.

Pellegrino CA, Morotti F, Untura RM, Pontes JH, Pellegrino MF, Campolina JP, Seneda MM, Barbosa FA, Henry M. 2016. Use of sexed sorted semen for fixed-time artificial insemination or fixed-time embryo transfer of in vitro-produced embryos in cattle. Theriogenology, 86:888-893.

Pereira MH, Wiltbank MC, Vasconcelos JL. 2016 Expression of estrus improves fertility and decreases pregnancy losses in lactating dairy cows that receive artificial insemination or embryo transfer. J Dairy Sci, 99:2237-2247.

Pontes JH, Nonato-Junior I, Sanches BV, ErenoJunior JC, Uvo S, Barreiros TR, Oliveira JA, Hasler JF, Seneda MM. 2009. Comparison of embryo yield and pregnancy rate between in vivo and in vitro methods in the same Nelore (Bos indicus) donor cows. Theriogenology, 71:690-697.

Pontes JH, Silva KC, Basso AC, Rigo AG, Ferreira CR, Santos GM, Sanches BV, Porcionato JP, Vieira PH, Faifer FS, Sterza FA, Schenk JL, Seneda MM. 2010. Large-scale in vitro embryo production and pregnancy rates from Bos taurus, Bos indicus, and indicus-taurus dairy cows using sexed sperm. Theriogenology, 74:1349-1355.

Pryce JE, Goddard ME, Raadsma HW, Hayes BJ. 2010. Deterministic models of breeding scheme designs that incorporate genomic selection. $J$ Dairy Sci, 93:5455-5466

Rando OJ, Simmons RA. 2015. I'm eating for two: parental dietary effects on offspring metabolism. Cell, 161:93-105.

Rasmussen S, Block J, Seidel GE Jr, Brink Z, McSweeney K, Farin PW, Bonilla L, Hansen PJ. 2013. Pregnancy rates of lactating cows after transfer of in vitro produced embryos using $\mathrm{X}$-sorted sperm. Theriogenology. 79:453-461.

Rexhaj E, Pireva A, Paoloni-Giacobino A, Allemann Y, Cerny D, Dessen P, Sartori C, Scherrer U, Rimoldi SF. 2015. Prevention of vascular dysfunction and arterial hypertension in mice generated by assisted reproductive technologies by addition of melatonin to culture media. Am J Physiol Heart Circ Physiol, 309:H1151-1156.

Schagdarsurengin U, Steger K. 2016. Epigenetics in male reproduction: effect of paternal diet on sperm quality and offspring health. Nat Rev Urol, 13:584-595.

Scherrer U, Rexhaj E, Allemann Y, Sartori C, Rimoldi SF. 2015. Cardiovascular dysfunction in children conceived by assisted reproductive technologies. Eur Heart J, 36:1583-1589.

Siqueira LG, Torres CA, Souza ED, Monteiro PL Jr, Arashiro EK, Camargo LS, Fernandes CA, Viana JH. 2009. Pregnancy rates and corpus luteum-related factors affecting pregnancy establishment in bovine recipients synchronized for fixed-time embryo transfer. Theriogenology, 72:949-958.

Siqueira LGB, Dikmen S, Ortega MS, Hansen PJ. 2017a. Postnatal phenotype of dairy cows is altered by in vitro embryo production using reverse $\mathrm{X}$-sorted semen. J Dairy Sci, 100:5899-5908.

Siqueira, LGB, Tribulo $P$, Chen $Z$, Denicol AC, Ortega MS,Negrón-Pérez WM, KannampuzhaFrancis J, Pohler KG, Rivera RM, Hansen PJ. 2017b. Colony stimulating factor 2 acts from Days 5 to 7 of development to modify programming of the bovine conceptus at day 86 of gestation. Biol Reprod, 96:743-757.

Son DS, Choe CY, Cho SR, Choi SH, Kim HJ, Hur TY, Jung YG, Kang HG, Kim IM. 2007. A CIDRbased timed embryo transfer protocol increases the pregnancy rate of lactating repeat breeder dairy cows. $J$ Reprod Dev, 53:1313-1318.

Stewart BM, Block J, Morelli P, Navarette AE, Amstalden M, Bonilla L, Hansen PJ, Bilby TR. 2011. Efficacy of embryo transfer in lactating dairy cows during summer using fresh or vitrified embryos produced in vitro with sex-sorted semen. J Dairy Sci, 94:3437-3445

Strata F, Giritharan G, Sebastiano FD, Piane LD, Kao CN, Donjacour A, Rinaudo P. 2015. Behavior and brain gene expression changes in mice exposed to preimplantation and prenatal stress. Reprod Sci, 22:2330

Thomasen JR, Willam A, Egger-Danner C, Sørensen AC. 2016. Reproductive technologies combine well with genomic selection in dairy breeding programs. $J$ Dairy Sci, 99:1331-1340.

Turner N, Robker RL. 2015. Developmental programming of obesity and insulin resistance: does mitochondrial dysfunction in oocytes play a role? $\mathrm{Mol}$ Hum Reprod, 21:23-30.

van Wagtendonk-de Leeuw AM, Aerts BJ, den Daas JH. 1998. Abnormal offspring following in vitro production of bovine preimplantation embryos: a field study. Theriogenology, 49:883-894

Vasconcelos JL, Jardina DT, Sá Filho OG, Aragon FL, Veras MB. 2011. Comparison of progesteronebased protocols with gonadotropin-releasing hormone or estradiol benzoate for timed artificial insemination or embryo transfer in lactating dairy cows. Theriogenology, 75:1153-1160.

Wagenaar K, Ceelen M, van Weissenbruch MM, Knol DL, Delemarre-van de Waal HA, Huisman J. 
2008. School functioning in 8- to 18 -year-old children born after in vitro fertilization. Eur J Pediatr, 167:12891295.

Watkins AJ, Platt D, Papenbrock T, Wilkins A, Eckert JJ, Kwong WY, Osmond C, Hanson M, Fleming TP. 2007. Mouse embryo culture induces changes in postnatal phenotype including raised systolic blood pressure. Proc Natl Acad Sci USA, 104:54495454.

Watkins AJ, Wilkins A, Cunningham C, Perry VH,
Seet MJ, Osmond C, Eckert JJ, Torrens C, Cagampang FR, Cleal J, Gray WP, Hanson MA, Fleming TP. 2008. Low protein diet fed exclusively during mouse oocyte maturation leads to behavioural and cardiovascular abnormalities in offspring. J Physiol, 586:2231-2244.

Wheeler MB, Rutledge JJ, Fischer-Brown A, VanEtten T, Malusky S, Beebe DJ. 2006. Application of sexed semen technology to in vitro embryo production in cattle. Theriogenology, 65:219-227. 